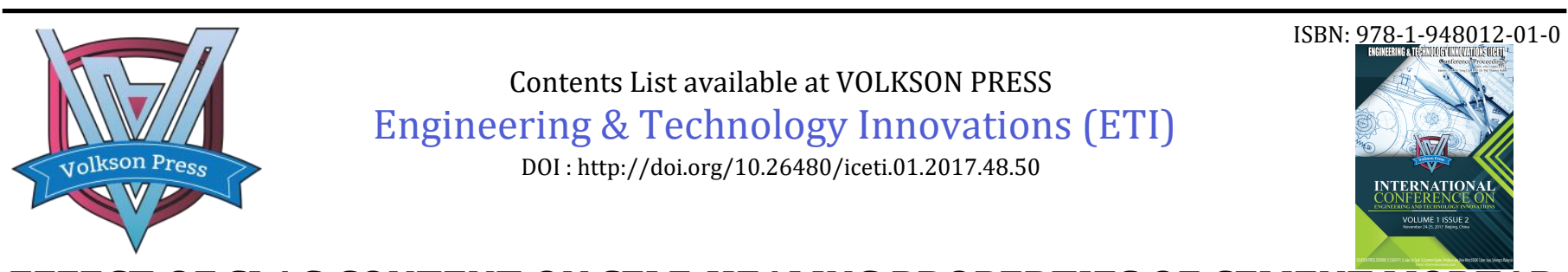

\title{
EFFECT OF SLAG CONTENT ON SELF-HEALING PROPERTIES OF CEMENT MORTAR
}

\author{
Ruihua Liang1, Lei Zhang1,2,3,Xiao Kou', Hui Rong1, Xueping Wang ${ }^{1}$
}

(1.College of Materials Science and Engineering, Tianjin Chengjian University, Tianjin 300384, China; 2.Key Laboratory of Soft Soil Engineering Character and Engineering Environment of Tianjin, Tianjin 300384, China; 3. Engineering Research Centre of Construction Waste and Coal Waste Recycle Technology of Tianjin, Tianjin 300384, China)

This is an open access article distributed under the Creative Commons Attribution License, which permits unrestricted use, distribution, and reproduction in any medium, provided the original work is properly cited

\section{ARTICLE DETAILS}

\section{Article History:}

Received 02 october 2017

Accepted 06 october 2017

Available online 11 october 2017

Keywords:

cement; slag; mortar; self-healing

\section{ABSTRACT}

The effects of different content $(10,20,30 \%)$ of slag on the hydration characteristics of cement and the self-healing properties of cement mortar were studied. The hydration heat, hydration products, mechanical properties and micro-structure of cement mortar were characterized by Digital cement hydration heat meter, X-ray diffraction (XRD), Ultrasonic nondestructive testing instrument and Scanning electron microscope (SEM) etc. The self-healing capacities of cracked cement mortar were characterized by strength restoration ratio and changes of ultrasonic wave. The results show that the accelerating period of cement hydration is prolonged with the increase of slag content; and the early hydration exothermic temperature decreased. The strength restoration ratio of mortar and the change of ultrasonic wave have similar laws, both of which decreased first and then increased with the increase of the content of slag, and the effect is best when the slag content is $30 \%$. The strength restoration ratio increases with increasing water in the curing conditions.

\section{INTRODUCTION}

Concrete as a quasi-brittle material, it is difficult to avoid cracking in the service environment. The survey shows that about one-fourth of these recently completed projects have quality problems, and $50 \%$ of them have concrete cracks ${ }^{[1]}$.In the early stage of micro-crack formation, if the crack can not be repaired in time, it will not only adversely affect the strength and durability of the concrete, but also cause the crack to deteriorate rapidly and even cause the brittle fracture of the concrete ${ }^{[2-4]}$. Proper use of self-healing properties of concrete can not only make the concrete with quality defects repaired, and even make the scrap concrete project come back to life [5-6], therefore, in recent years, self-healing concrete has become a hot spot.Then, the current slag is often used in high-strength concrete and high performance concrete, with slag to replace part of cement, not only can save cement, reduce pollution and reduce costs, but also Improve the properties of concrete, especially in terms of improving durability [7].When the cement mixed with a certain amount of slag, the hydration of cement and self-healing properties become more complex ${ }^{[8-9]}$, Therefore, it is necessary to further study the cement hydration law, concrete strength and self-healing performance.In this paper, the influence of different contents of slag on the hydration and self-healing properties of cement mortar was studied.And improve the performance of concrete, so as to better serve the actual project.

\section{Experimental}

\subsection{Raw materials}

Commercial cement for the test of ordinary portland cement P.042.5Rwith a specific surface area of $325 \mathrm{~m}^{2} / \mathrm{kg}$, a standard consistency of $27.4 \%$, initial setting time of $158 \mathrm{~min}$, final setting time of $258 \mathrm{~min}$, chemical composition shown in Table 1; The chemical composition of the slag used in Table 1; sand with standard sand and ordinary river sand, fineness modulus of 2.9. Mixing water is tap water.

Tab 1 Chemical composition of commercial cement and slag/wt $\%$

\begin{tabular}{lllllllll}
\hline $\begin{array}{l}\text { Composi } \\
\text { tions }\end{array}$ & $\mathrm{SiO}_{2}$ & $\begin{array}{l}\mathrm{Fe}_{2} \mathrm{O} \\
3\end{array}$ & $\mathrm{Al}_{2} \mathrm{O}_{3}$ & $\mathrm{CaO}$ & $\mathrm{MgO}$ & $\mathrm{K}_{2} \mathrm{O}$ & $\begin{array}{l}\mathrm{Na}_{2} \\
0\end{array}$ & $\mathrm{SO}_{3}$ \\
\hline $\begin{array}{l}\text { P.042.5 } \\
\text { slag }\end{array}$ & 18.52 & 3.84 & 5.58 & 54.00 & 4.52 & 0.74 & 0.19 & 3.57 \\
\hline
\end{tabular}

\subsection{Preparation of test blocks and cracks of cement mortar}

CementK10, cement $\mathrm{K} 20$ and cement K30 were prepared by adding $10 \%$, $20 \%$ and $30 \%$ slag respectively in commercial cement,A mortar block of $40 \mathrm{~mm} \times 40 \mathrm{~mm} \times 160 \mathrm{~mm}$ was prepared with cement K10, cement K20 and cement K30 in a proportion (cement: standard sand: water $=1: 3$ 0.5).After standard curing for $28 \mathrm{~d}, 56 \mathrm{~d}$ and $118 \mathrm{~d}$,The compressive strength and ultrasonic wave velocity of the test piece were measured. The 28-day mortar block was pre-cracked and marked, and then the compressive strength and ultrasonic wave velocity were measured after 28 days and 90 days. The prefabricated cracks were prepared by mortar test pieces. After curing for 28 days, the specimens were placed on the pressure table and pressed on the sides. The test pieces were repeatedly pressed three times with $90 \%$ the ultimate pressure of the test pieces.

\subsection{Testing and characterization}

\subsubsection{Determination of hydration heat}

The PTS-12S digital cement hydration heat tester produced by Wuhan Botai New Technology Co, Ltd is used to analyze the difference of exothermic heat of cement in early stage.

\subsubsection{Determination of hydration product}

The type of hydrated product was measured using an Ultima IV X-ray diffractometer produced by Nippon Polytechnic Co, The instrument used copper target, wavelength $\lambda=0.154 \mathrm{~nm}$, working voltage $40 \mathrm{Kv}$, operating current $40 \mathrm{~mA}$, scanning range 5-80 degrees, scanning speed 10 degrees / min, step 0.02 degrees / step.

\subsubsection{Strength restoration ratio}

Test equipment for the Wuxi Instrument and Equipment Co.,Ltd., produced by TYE-2000B-type pressure testing machine. The formula for calculating the 28-day strength restoration ratio $\psi$ is given in Equation 1,

$\psi=\left[\left(\bar{f}_{90 d}-f_{28 d}\right) /\left(f_{118 d}-f_{28 d}\right)\right] \times 100 \%$

( $\%$ represents the pre-crack test piece strength restoration ratio, $\boldsymbol{f}_{28 d}$ represents the test piece $28 \mathrm{~d}$ compressive strength, $f_{11 \mathrm{~s}}$ represents test piece $118 \mathrm{~d}$ compressive strength, $\bar{f}_{90 d}$ represents the pre-crack test piece $90 \mathrm{~d}$ after repair of compressive strength) 2.3.4 Determination of ultrasonic wave velocity 
The ultrasonic wave velocity of mortar block was measured by TICO concrete ultrasonic tester. After the pre-crack maintenance $n$ days, the formula for calculating the changes of ultrasonic wave is shown as formula 2 ,

$\varphi_{n}=\left[\left(\bar{v}_{n}-v_{28}\right) /\left(v_{n+28}-v_{28}\right)\right] \times 100 \%$

( $\nu_{28}$ represents the 28-day ultrasonic wave velocity of the test piece without cracks, $\bar{v}_{n}$ represents the ultrasonic wave velocity of the test piece after $\mathrm{n}$ days after the prefabricated cracks are maintained, $v_{n+28}$ represents the ultrasonic wave velocity of the test piece $(n+28)$ days without cracking)

\subsubsection{SEM analysis of hydration product morphology}

The morphology of the hydration products at the fracture section was measured with a JSM-7800F field emission SEM manufactured by JEOL Ltd. The fracture surface morphology was observed at a pressure of $5 \mathrm{kV}$ and a magnification of 2000 .

\section{Experimental results and discussion}

\section{1 hydration heat}
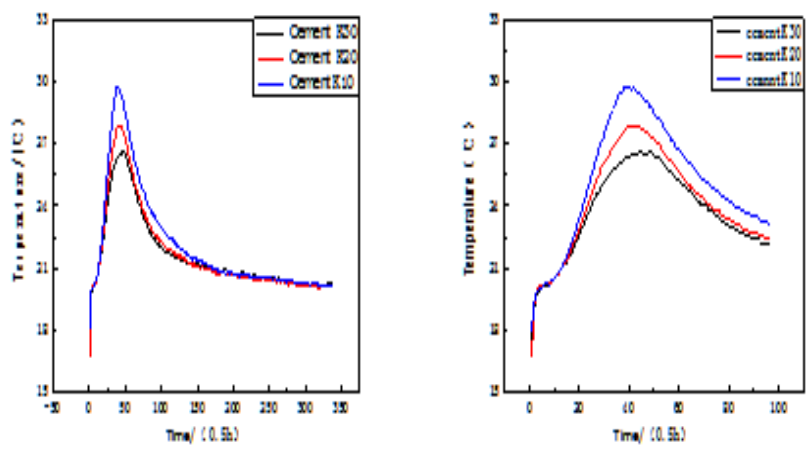

(a) Cement hydration for 7 day

(b) 48 hours of cement hydration

Fig.1 Hydration of cement with different content of slag

From the 7-day hydration curve in Fig. 1 (a), it can be seen that the induction period of the cement hydration process is short and not obvious. The hydration process mainly includes acceleration, deceleration and stabilization. The acceleration period lasted for $20-23 \mathrm{~h}$ and the deceleration period lasted for $18-25 \mathrm{~h}$. The steady-state process curve almost coincided. Within a certain range, the higher the slag content, the lower the peak value of early exothermic hydration temperature, and the difference is large. Cement hydration heat within 3 days after mixing the fastest heat, the amount of different three cement can reach the exothermic peak, and into the stable period.

From Figure 1 (b) cement and water mixing within $48 \mathrm{~h}$ of hydration heat can be seen in the early hydration process of cement differences in the process of hydration. The induction period of cement hydration is not obvious, and the accelerating period lasts longer. The accelerating period of cement K10, K20 and $\mathrm{K} 30$ was $20 \mathrm{~h}, 21 \mathrm{~h}$ and $22.5 \mathrm{~h}$, the peak value of exothermic temperature was $29.71^{\circ} \mathrm{C}, 27.88^{\circ} \mathrm{C}$ and $26.59^{\circ} \mathrm{Crespectively.}$ Within a certain range, with the increase of the slag content, the cement hydration accelerating period increased, and the exothermic temperature peak value decreased. The difference of the exothermic temperature of hydration is different when the dosage is different, and it can be seen that the effect of the slag content on the hydration heat of early cement is great.

\section{2 hydration products}

The results of XRD analysis of cement hydrated products with slag are shown in Fig. 2,

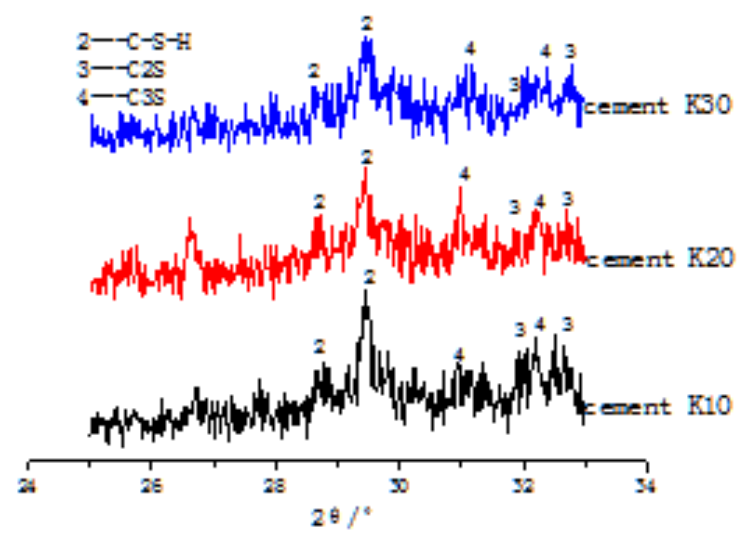

Fig. 2 XRD of the $25-33^{\circ}$ section of the 28 -day cement paste block

The content of C-S-H gel in the hydration product of cement decreased with the increase of the slag content, and the degree of early hydration decreased. The contents of $\mathrm{C}_{3} \mathrm{~S}$ and $\mathrm{C}_{2} \mathrm{~S}$ in the test pieces decrease with the increase of the slagcontent. When the slag is added into the cement, it has a certain physical filling effect, and also affects the crystallization rate and crystallization degree of $\mathrm{Ca}(\mathrm{OH})_{2}$.

\subsection{Strength restoration ratio}

The change of compressive strength and strength restoration ratioof cement under different curing conditions is shown in Figure 3.

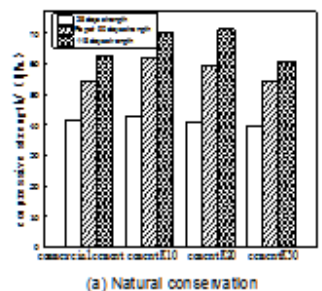

(a) Natural conse vation

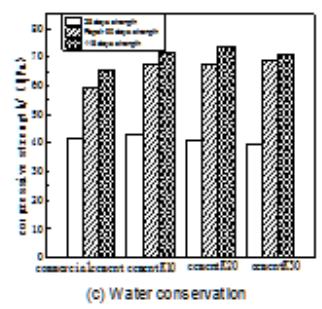

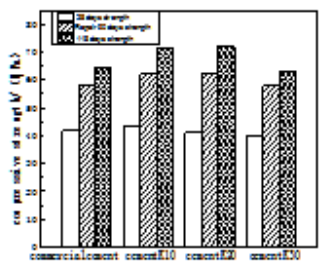

(b) Standard conservation

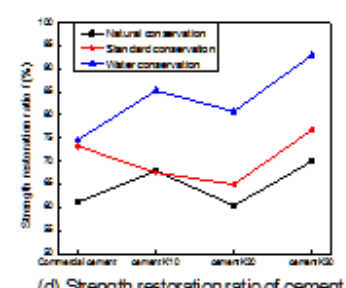

Fig.3 The compressive strength and strength restoration ratio of cement under different curing conditions

It can be seen from Fig. 3 that the strength restoration ratio of test pieces made by cement K10, K20 and $\mathrm{K} 30$ are $67.9 \%, 60.4 \%$, 70\% respectively under natural curing condition,The recoveries were $67.5 \%, 65 \%, 76.8 \%$ under standard curing conditions, The recoveries of strength were $85.3 \%$, $80.8 \%$ and $93 \%$ under water curing conditions. the content of $10 \%$ when the test piece 28 days the highest intensity. With the same curing condition, the strength of the cement mortar block after the pre-crack has been restored. With the increase of the slag content, the strength restoration ratio of the test piece decreases first and then increases. When the content of slag is $30 \%$, the repairing effect is the best. The strength restoration ratio increases with the increase of the moisture supply in the curing condition. Adequate water supply, more conducive to the secondary hydration reaction, the formation of hydration products filled cracks, so that a more complete structure.

\subsection{Changes of ultrasonic wave}

The changes of ultrasonic wave of different cement mortar test pieces under different curing conditions show in Figure 4. 


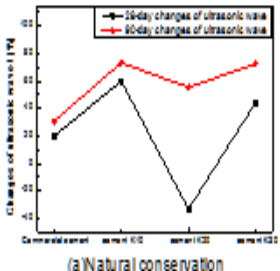

(a) Natural conservation

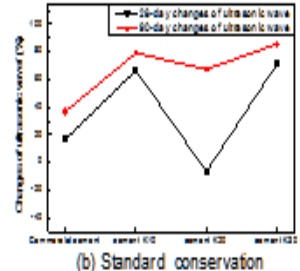

(b) Standard conservation

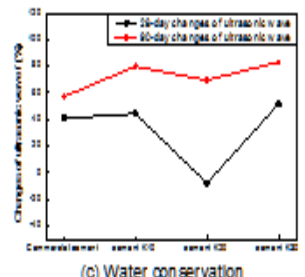

Fig.4 Changes of ultrasonic waveof cement mortar block with different amount of slag

From Fig.4, it can be seen that the changes of ultrasonic wave of the cement block K10, K20 and K30 under the natural curing conditions are 60\%, $33.3 \%, 44.5$ and $73.33 \%, 55.56 \%$ and $72.41 \%$ respectively at $28 \mathrm{~d}$ and $90 \mathrm{~d}$, The changes of ultrasonic wave at the 28 th and 90th days were 66.67 , $6.45,71.43$ and $79.17 \%, 67.5 \%$ and $85.71 \%$ respectively In standard curing conditions.The changes of ultrasonic wave at the 28th and 90 th day were $44.6 \%,-7.69 \%, 51.72 \%$ and $80 \%, 69.57 \%$ and $86.33 \%$ respectively under the condition of water conservation.

The results are as follows: 1) Under the same curing conditions, the changes of ultrasonic wave decreases first and then increases with the increase of the slag content, and the changes of ultrasonic wave is the best when the content of the slag is $30 \%$. The changes of ultrasonic wave is much lower than that of commercial cement and K10 block and K30 test piece at 28 days, and after 90 days is more than that of commercial cement. , Indicating that the slag participate in the latter part of the reaction, to improve the structure of compactness. 2) Comparing the changes of ultrasonic wave of different conservation conditions, it can be seen that before 28 days, the recovery rate of the test pieces with different dosage under the standard curing condition is the best. At 90 days, with the increase of the water supply in the curing environment, the changes of ultrasonic wave is increased and the changes of ultrasonic wave is the best under water conservation. Water sufficient environment, more conducive to the secondary hydration reaction, the formation of hydration products fill the pores, so that the structure is more compact.

\subsection{Microstructure}

SEM analysis can be more intuitive to see the fracture section of the healing situation. The results of SEMof the cement mortar with different content of slag in 90 days were shown in Fig. 5 (2000 ×).

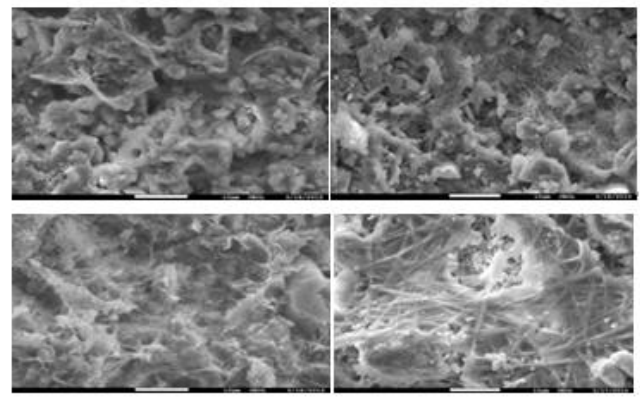

(a)SEM images of test piece made of commercial cement

(b) SEM image of test piece made of cement K10

(c) SEM image of test piece made of cement K20

(d) SEM image of test piece made of cement K30

Fig.5 SEM images of cracks in 90 days of mortar test pieces with different amount of slag in water
From the SEM images, it can be seen that under the condition of water curing, the cross section of the fracture is different when the content of the slag is not same. When the content of the slag is $10 \%$, the fracture section produces a lot of fibrous gel; , A large amount of gel and fibrous gel were formed in the fracture section. When the content of the slag was increased to $30 \%$, a lot of fibrous gel and flaky gel were formed in the fracture section, and the structure was compact. Within a certain range, The higher the content, the better the gel formation.

\section{Conclusion}

The results of the study on the hydration characteristics of cement and the self-healing property of cement mortar are as follows:

(1) The induction period of cement with slag is very short during the hydration process.The accelerating time of cement with $10 \%, 20 \%$ and $30 \%$ slag was $20 \mathrm{~h}, 21 \mathrm{~h}$ and $22.5 \mathrm{~h}$, respectively. The exothermic peak temperature was $29.71{ }^{\circ} \mathrm{C}, 27.88^{\circ} \mathrm{C}, 26.59^{\circ} \mathrm{C}$.Within a certain range, the accelerating period of cement hydration is prolonged with the increase of slag content, early hydration exothermic peak temperature is lower.

(2) The content of C-S-H gel decreased with the increase of slag content, and the degree of early hydration decreased. The contents of $\mathrm{C}_{3} \mathrm{~S}$ and $\mathrm{C}_{2} \mathrm{~S}$ in the test pieces decrease with the increase of the slag content.

(3) The strength of the test piece was the highest at 28 days.Under the same curing condition, with the increase of the slag content, the strength restoration ratioof the test piece decreases first and then increases, and the repairing effect is the best when the content of the slag is $30 \%$. The strength restoration ratio increases with increasing moisture in the curing conditions.

(4) Under the same curing conditions, the changes of ultrasonic wave decreases first and then increases with the increase of the slag content, and the changes of ultrasonic wave is the best when the content of the slag is $30 \%$.

(5) Under the same curing condition, the cross section of the fracture is different when the content of the slag is different, and the higher the content of the slag is, the better the gel formation is.

\section{Acknowledgements}

We gratefully acknowledge the support of this research by Tianjin Application foundation and Advanced Technology Research Program (Grant No. 14JCZDJC40800) and the National Natural Science Foundation of China (Grant No. 51372163)

\section{References}

[1]Xuejun Zhang.Investigation on the self-healing of cementitious materials [D]. Wuhan University of Technology, 2012,5.

[2]Hui Yang. Study and progress of crack self-healing of concrete[J]. China Building Materials Science \& Technology, 2011,2: 66-70.

[3]Wenke Yang (a). Modern concrete science problems and research [M]. Beijing: Tsinghua University Press, 2012.6.

[4]Song G,Mo YL.Increasing concrete structural survivability using smart materials. A proposal submitted to Grants to Enhance and Advance Research (GEAR), University of Houston, January 2003.

[5]AhnTH.Development of self-healing concrete incorporating geomaterials: a study on its mechanism and behavior in cracked concrete. $\mathrm{PhD}$ dissertation, Department of Civil Engineering[D], The University of Tokyo, Japan, 2008.

[6]Mustafa Sahmaran,Gurkan Yildirim,Tahir K.Erdem.Self-healing capability of cementitious composites incorporating different supplementary cementitious materials.The Autogenous Healing of Concrete and Mortars[J].Cement and Concrete Composites ,2013,35:89101.

[7]Wan Xiao, Hong-wen Ma.The influences of slag ultrafine powder on the cement hydration products [J].Acta Petrologica Et Mineralogica,2013,11: 882-888.

[8]Yang Lu,Gen Li,Xueke Xie, et al. Research progress on the influence of slag on cement hydration [J]. Bulletin of the Chinese Ceramic Society, 2013, 32 (12): 2528-2532 